\title{
REFLEXÃO SOBRE A PANDEMIA E TECNOLOGIAS: EFEITOS DA COVID-19 PARA A EDUCAÇÃO E SAÚDE ${ }^{1}$
}

\author{
REFLECTION ON PANDEMIA AND TECHNOLOGIES: \\ EFFECTS OF COVID-19 FOR EDUCATION AND HEALTH
}

\author{
Antonio Paulo Valim Vega ${ }^{2}$, Ana Zilda de Castro Reck ${ }^{3}$ e Tais Steffenello Ghisleni ${ }^{4}$
}

\section{RESUMO}

Esse trabalho realiza uma breve análise de três produções instrucionais "cartilhas" produzidas e publicadas no portal de Instituições de Ensino Superior, com o objetivo de refletir sobre o papel das tecnologias de informação e comunicação para e educação e saúde motivada pela pandemia da COVID-19. O estudo contempla um aporte teórico sobre a comunicação, considerando que a análise das publicações e contexto se apoiam nos pressupostos desse campo de estudo. Utilizou-se no estudo uma abordagem de pesquisa qualitativa descritiva do tipo exploratória, evidenciando que a oferta colaborativa por parte das IES em momento de pandemia é uma questão ética e de responsabilidade sócio ambiental.

Palavras-chave: Midiatização; TIC’s; Produção didática; Coronavírus.

\section{ABSTRACT}

This paper aims to briefly analyze three instructional productions "booklets" produced and published on the Higher Education Institutions portal, with the aim of reflecting on the role of information and communication technologies for education and health motivated by the COVID - 19 pandemic. The study contemplates a theoretical contribution on communication, considering that the analysis of publications and context are based on the assumptions of this field of study. An exploratory, descriptive qualitative research approach was used in the study, showing that the collaborative offer by HEIs in a time of pandemic is a matter of ethics and socio-environmental responsibility.

Keywords: Mediatization; ICTs; Didactic production; Coronavirus.

\footnotetext{
${ }^{1}$ Trabalho realizado nos estudo e programas de pesquisa do Mestrado em Ensino de Humanidades e Linguagens

2 Pedagogo, Mestre em Ensino de Humanidades e Linguagens - MEHL, Universidade Franciscana - UFN. E-mail: paulovega1010@gmail.com

${ }^{3}$ Enfermeira, especialista em Saúde da Família e Comunidade, Prefeitura Municipal de Eldorado do Sul /RS. E-mail: anazreck@gmail.com

4. Dra em Comunicação. Professora do Curso de Publicidade e Propaganda e do Mestrado em Ensino de Humanidades e Linguagens - MEHL Universidade Franciscana. E-mail: taisghileni@yahoo.com.br
} 


\section{INTRODUÇÃO}

Há duas décadas, adentramos o século XXI marcados por um forte esquema globalizado que compreende enormes desafios e problemas não resolvidos de séculos passados, que ainda carregamos, muitos destes, criados pela própria ação do homem. Outras questões, são contemporâneas, produtos do mundo globalizado da modernidade tardia ou pós-modernidade como definem alguns autores, e por isso, exigem que olhemos através de nova lentes, as desigualdades entre grupos, populações e nações, os problemas socioambientais, a mudança climática, a séria crise sanitária e de saúde que vivenciamos em proporções globais desde os primeiros dias deste ano de 2020, encaminham reflexões múltiplas.

O coronavírus entrou em cena em dezembro de 2019 em Wuhan, na China, onde a doença foi detectada pela primeira vez, alastrou-se a outros continentes e chegou ao Brasil em meados de março 2020, desde então, tem-se vivido o inesperado, a pandemia, a quarentena, o isolamento social, o medo, a desconfiança. O mundo parou, os índices de preços e valores dos negócios perderam as referências, o caos e a confusão nunca foram tão evidentes.

Tudo isso confirma que existem muitas áreas e esferas da vida que dizem respeito à dignidade humana, ao respeito e aos direitos a uma vida com qualidade e dignidade que não estão diretamente ligadas a questões de renda ou economia, e essa crise na saúde veio deixar tudo a descoberto, e isso, está a promover uma grande reflexão.

A pandemia da COVID-19 trouxe à tona a necessidade de informações básicas de cuidados e práticas de saúde, que em muitos casos e por razões diferentes não fazem parte da vida diária das pessoas, como por exemplo, a higienização das mãos. Uma atividade corriqueira para os profissionais da saúde, mas que grande parte da população não tem como prática em seu cotidiano, evidenciando entre outras questões, que há um problema estrutural de saneamento e esgoto na maioria das cidades brasileiras que deixa milhares de pessoas sem as condições básica de higienização, algo que a pandemia deixa transparecer, além da falta de acesso à informação e a processos educacionais em saúde.

Nunca foi tão urgente e evidente a necessidade de tratar os problemas de saneamento tanto para resolver o problema de água potável quanto a coleta de esgoto, o que implica sérios problemas de saúde, afetando e ampliando o fosso da pobreza e desigualdade social. Diante de um cenário que apresenta muitas questões se degradando, intercambiando doença do ambiente com a doença das pessoas, fica-se a buscar as alternativas e possibilidades de aprendizagem que um evento dessa natureza pode apresentar, e então, pensa-se nas tecnologias e suas possibilidades. Com isso nosso objetivo é refletir sobre o papel das tecnologias de informação e comunicação para a educação e saúde no cenário da pandemia causada pela COVID 19.

A situação do saneamento tem problemas e reflexos imediatos nos indicadores de saúde. A COVID-19 evidencia que esse cenário é dos problemas agravantes e também um dos desafios para a gestão pública, requer consciência, parcerias, participação da sociedade civil, desenvolver capacidades de 
cidadania o que inclui desafios para a educação, o ensino e aprendizagem. Todos precisam aprender, com esse processo a "pandemia". Aprender nesse contexto, não é uma escolha, é uma necessidade fundamental.

De acordo com Morin (2020) a epidemia nos traz um festival de incertezas, não conhecemos a origem do vírus, e nem quais mutações poderá passar, não se tem nenhuma medida ou parâmetro que indique qual o caminho mais seguro, ou quão próximo se está da sua regressão ou permanência. "Não sabemos quais serão as consequências políticas, econômicas, nacionais e globais, das restrições trazidas por confinamentos. Não sabemos se devemos esperar o pior, o melhor, uma mistura dos dois: estamos caminhando para novas incertezas" (MORIN, 2020).

O autor anuncia que se está a caminhar para novas incertezas, e uma evidencia se sobressai e confirma a crise. É uma crise de complexidade tamanha, a revelar que as deficiências e reducionismos do conhecimento inculcados do passado, não encontram suas referências, perderam-se na "revelação avassaladora das mudanças pela quais estamos passando, é que tudo o que parecia estar separado esta ligado, pois, uma catástrofe na saúde traz catástrofes em cadeia para tudo que é humano" (MORIN, 2020).

Talvez esse atributo caótico do momento "a pandemia" por seu inesperado que é, e está sendo; pela sua relação estreita com tudo que se está a debater neste estudo, e que diz respeito ao homem, ao ambiente, a saúde, a qualidade de vida e que, até então, tratava-se de pensar a doença, do ambiente, falava-se da crise e do quão complexa é. E eis que surge o inesperado com a pandemia, a ofertar e anunciar a contragosto que uma nova relação de extrema complexidade emergiu, com rapidez estonteante, a relação da qual se falava e as competências exigidas que até então se voltavam a fatores exógenos, agora, é uma relação opressora e endógena, e da mesma forma diz respeito ao homem, porém, o ambiente doente é o próprio homem e quais competências são necessárias de serem ampliadas para juntar-se àquelas já anunciadas para resolver a crise ambiental.

O que leva a pensar um "novo caminho político-ecológico-econômico-social guiado pelo humanismo regenerado" (MORIN, 2020). Com isso se multiplicariam verdadeiras reformas, nada estruturais, mas, as reformas da vida, a falar de solidariedade, cooperação e da necessidade básica de sustentabilidade e de tudo que produz satisfação e qualidade de vida.

Entretanto, a pandemia apresenta uma condição surpreendente é o fato da comunicação e os dispositivos móveis estarem suprindo a necessidade de as pessoas interagir e dialogar, de outra forma, sem o auxilio das tecnologias de comunicação esse momento seria insuportável.

\section{A COMUNICAÇÃO: UMA ALIADA DA EDUCAÇÃO E SAÚdE EM TEMPOS DE PANDEMIA}

A comunicação é um tipo distinto de atividade social que envolve a produção, a transmissão e a recepção de formas simbólicas e implica a utilização de recursos de vários tipos. De acordo com Thompson (1998), na produção e transmissão de formas simbólicas sempre se utiliza de um meio 
técnico. Este é um elemento material com que, ou por meio do qual a informação ou o conteúdo simbólico é fixado e transmitido do produtor para o receptor.

Todos os processos de intercâmbio envolvem um meio técnico de algum tipo. Um dos atributos dos meios técnicos é o que permite algum grau de fixação ou a preservação da forma simbólica em um meio que possui graus variáveis de durabilidade. Um segundo atributo é o que permite um certo grau de reprodução, ou seja, a capacidade de multiplicar cópias de uma forma simbólica. A reprodutibilidade das formas simbólicas diz do seu poder de comercialização potencializado pelo grau de reprodutibilidade.

Um terceiro aspecto dos meios técnicos é que eles permitem um certo grau de distanciamento espaço temporal, compreendido como um afastamento. Dessa forma o uso de meios técnicos dá as pessoas novas forma de organizar, controlar e usar o espaço e o tempo, assim como pode proporcionar que as pessoas experimentem a vida social numa perspectiva nova de espaço e tempo.

Os meios de comunicação possuem uma dimensão simbólica inquestionável, estão intrinsecamente ligados à produção, armazenamento e a circulação de materiais que tem importância para as pessoas que produzem, assim como, para os que recebem esse conteúdo. Por isso, alerta Thompson (1998), que a preocupação a respeito da comunicação não pode se restringir aos aspectos técnicos, a dimensão simbólica tem um papel de relevância a ser considerado, a despeito da relevância dos aspectos técnicos, e estes,

[...] não deveriam, porém, obscurecer o fato de que o desenvolvimento dos meios de comunicação é, em sentido fundamental, uma reelaboração do caráter simbólico da vida social uma reorganização dos meios pelos quais a informação e o conteúdo simbólico são produzidos e intercambiados no mundo social e uma reestruturação dos meios pelos quais os indivíduos se relacionam entre si (THOMPSOM, 1998, p. 19).

Para Castels (2013), a comunicação é um processo de compartilhamento de significados dados nas informações. Afirma que para a sociedade em geral a comunicação representa a principal fonte de produção social de significados, produzindo com isso o processo de comunicação socializado. Uma compreensão daquilo que existe e é de domínio público, mas, que extrapola a comunicação interpessoal, um efeito da transformação contínua das tecnologias de comunicação e informação na era digital. Dessa forma, tem se ampliado os domínios da comunicação que rapidamente vai permeando o tecido social, numa rede que é ao mesmo tempo local e global, num processo contínuo de mudanças.

Nos últimos anos, a mudança fundamental no domínio da comunicação foi a emergência do que chamarei de autocomunicação - o uso da internet e das redes sem fio como plataformas da comunicação digital. É comunicação de massa porque processa mensagens de muitos para muitos, com o potencial de alcançar uma multiplicidade de receptores e de se conectar a um número infindável de redes que transmitem informações digitalizadas pela vizinhança ou pelo mundo. (CASTELLS, 2013, p. 24). 
Braga (2009) explica que a comunicação é um fenômeno que não depende de códigos prontos, pois a comunicação é um processo que se dá por transformação na interação. Reconhece que a interação é dada num sistema de signos, no entanto, acredita na renovação permanente desses sistemas de linguagem e dos sistemas de regras que vão se recodificando em cada conjunto de circunstâncias históricas, dependentes de seus objetivos, potencial criativo, códigos institucionais e instituídos, os quais se encontram em formação e transformação contínua.

Os estudos de Gomes (2016) informam que o relacionamento da mídia com os processos de significação e com os processos socioculturais deixa amostra uma realidade que acontece naquilo que se chama de "marco dos processos midiáticos". Sendo que esses movimentos, ao interagir contribuem para a construção e significado do sentido social, ou seja a elaboração e produção de resultados práticos e simbólicos dadas no processo de comunicação que envolve a circulação de conteúdos midiatizados e ressignificados por indivíduos e sociedades.

Em relação a isso, Gomes (2016) denomina de "cadinho da cultura" onde os diversos processos sociais acontecem. É esse ambiente, tecnologizado/midiatizado, que ao mesmo tempo em que proporciona uma mudança é também modificado por estas, ou seja, um novo modo de ser que nasce pela midiatização, impacta e transforma o ambiente, as pessoas e os tipos de interação, as inter-relações adquirem uma dimensão qualitativamente superior em relação ao espaço e tempo. Contudo, pode-se dizer que esse é um percurso que vai dando forma a midiatização e configurando um novo mundo e também um novo ser humano, numa sucessão contínua de mudanças e transformações. Para deixar mais claro as dimensões da comunicação envolvidas na midiatização, traz-se o quadro, de Pierre Lévy na sua publicação Cibercultura de 1999, mas ainda válida no sentido da respectiva histórica e que nos possibilita visualizar o presente.

Quadro 1 - Diferentes dimensões da comunicação.

\begin{tabular}{|c|l|l|}
\hline MEIO & \multicolumn{1}{|c|}{ DEFINIÇÃO } & \multicolumn{1}{c|}{ EXEMPLO } \\
\hline Mídia & $\begin{array}{l}\text { suporte de informação e } \\
\text { de comunicação }\end{array}$ & $\begin{array}{l}\text { Impressos, cinemas, rádio, televisão, telefone, CD-ROM, Internet, (computadores + } \\
\text { telecomunicação) etc. }\end{array}$ \\
\hline $\begin{array}{c}\text { Modalidade } \\
\text { perceptiva }\end{array}$ & $\begin{array}{l}\text { sentido implicado pela } \\
\text { recepção da informação }\end{array}$ & visão, audição, tato, odor, gosto e cinestesia. \\
\hline Linguagem & tipos de representação & Línguas, músicas, fotografias, desenhos, imagens, animados, símbolos e dança. \\
\hline podificação & $\begin{array}{l}\text { principio do sistema de } \\
\text { gravação e de transmissão } \\
\text { das informações }\end{array}$ & Analógico e digital. \\
\hline $\begin{array}{c}\text { Dispositivo } \\
\text { informacional }\end{array}$ & $\begin{array}{l}\text { relação entre elementos } \\
\text { de informação }\end{array}$ & $\begin{array}{l}\text { Mensagens com estruturas lineares (textos clássicos, música, filmes), mensagens } \\
\text { com estrutura em rede (dicionários, hiperdocumentos), mundos virtuais (a } \\
\text { informação é o espaço contínuo), o explorador ou seu representante estão } \\
\text { imersos no espaço) e fluxos de informações. }\end{array}$ \\
\hline $\begin{array}{c}\text { Dispositivo } \\
\text { Comunicacional }\end{array}$ & $\begin{array}{l}\text { relação entre os partici- } \\
\text { pantes da comunicação }\end{array}$ & $\begin{array}{l}\text { Dispositivo um todos em estrela (imprensa, rádio e televisão), dispositivo } \\
\text { um-um em rede (correio, telefone), dispositivo todos-todos, no espaço (conferên- } \\
\text { cias eletrônicas, sistemas para ensino ou trabalho cooperativo, mundos virtuais } \\
\text { com diversos participantes, WWW) }\end{array}$ \\
\hline
\end{tabular}


Olhar a comunicação a partir do quadro sugerido por Pierre Lévy, é uma forma de analisar as dimensões da comunicação e também pensar a sua evolução em torno das tecnologias e diversos dispositivos comunicacionais com relação aos produtores e participantes e interagentes dos conteúdos que integram o processo comunicacional.

\section{ASPECTOS METODOLÓGICOS}

Essa pesquisa apresenta uma abordagem qualitativa descritiva do tipo exploratória. Complementada por uma revisão bibliográfica planejada, buscando atender um contexto e situação específica, utiliza de métodos sistemáticos para analisar os dados identificados.

Segundo Minayo (2007) e Gil (2017), as pesquisas qualitativas permitem que o pesquisador possa realizar uma análise crítica e aprofundada sem a necessidade de quantificar os resultados, outra perspectiva da pesquisa qualitativa segundo Batista (1999), é que os dados na pesquisa qualitativa se dão em um contexto fluente de relações, são colhidos interativamente em processos flexíveis em que se encaixam os dados analisados.

Assim foram selecionadas, por conveniência, três cartilhas que são resultado de produções instrucionais para contribuir com o acervo de saberes sobre a pandemia em decorrência da COVID-19, olhando principalmente para o conteúdo, seu propósito e objetivo, mas também lançando um olhar analítico sobre outros aspectos da produção em decorrência da proposta, contexto e meio de veiculação em que situam-se as referências do estudo sobre comunicação e tecnologias. Foram criadas, portanto, categorias de análise. São elas: objetividade e conteúdo; conhecimento da audiência e adequação; confiabilidade, e aparência, estética e linguagem.

\section{REFLEXÕES DO ESTUDO}

Com a pandemia a área das tecnologias de informação e comunicação adquirem uma dimensão maior ainda e são potencializados seus recursos e usos em processos de informação, ensino, saberes, escolares, acadêmicos e em saúde. Os processos educacionais foram totalmente arrebatados pela característica remota como convém ao afastamento social tão necessário para ajudar a conter o avanço da COVID-19. Em paralelo, a comunicação auxilia a todos como meio de compartilhamento, interação e socialização que contribui com a saúde mental das pessoas diante de um cenário de afastamento para o qual ninguém estava preparado.

A mídia aparece como suporte de informação e comunicação, então a midiatização pode ser encarada como a utilização em larga escala desses suportes de informação e comunicação. Nesse sentido, a midiatização vai se afirmando cada vez mais como um conceito para anunciar o momento presente e as mudanças e transformações sociais e culturais. A midiatização é uma terminologia 
empregada para a definição de um contexto e circunstâncias quando se trata de comunicação e seus efeitos nesta contemporaneidade.

Castells (2012) reconhece que existe, uma característica comum a todos os processos de construção simbólica: eles dependem amplamente das mensagens, que são estruturas criadas, formatadas e difundidas nas redes de comunicação multimídia. Noutra perspectiva Thompson (1998) alerta que somente é possível entender o impacto e desenvolvimento das novas redes de comunicação e do fluxo de informação se deixarmos de lado a ideia simplista de que os meios de comunicação servem apenas para transmitir informações e conteúdo simbólico. Ao contrário: Nós iremos ver, ao invés, que o uso dos meios de comunicação implica a criação de novas formas de ação e de interação no mundo social, novos tipos de relações sociais e novas maneiras de relacionamento do indivíduo com os outros e consigo mesmo (THOMPSON, 1998, p. 13).

Se a comunicação é uma forma de ação, a análise da comunicação deve se basear, pelo menos em parte, na análise da ação e na consideração do seu caráter socialmente contextualizado, esse é o entendimento de Thompson (1998), no qual baseamos o estudo, que nos leva a refletir sobre o presente, contexto em que as comunicações amparadas nos dispositivos digitais midiatizados potencializam a comunicação e nesse momento são fatores que colaboram para a saúde da população, pois, conferem à aceitação do afastamento social uma condição de educação, instrução, isto é, aprender outra formas de interação e socialização, importante para evitar e atenuar estresse e desassossego que a pandemia instaura em todos.

A ação que se analisa especialmente no instante que acompanha a pandemia, situa-se em relação a produção e publicação de conteúdos, grande parte das instituições de ensino superior produziram e publicaram material em suas páginas na internet para contribuir com a população sobre as formas de prevenir o contágios com o "coronavírus (uma família de vírus que causam infeções respiratórias), COVID-19 (é uma doença causada pelo coronavírus SARS-CoV-2), apresenta um quadro clínico que varia de infecções assintomáticas e quadros respiratórios graves" (CARTILHA UFN).

Quadro 2 - Produções de material instrucional por IES.

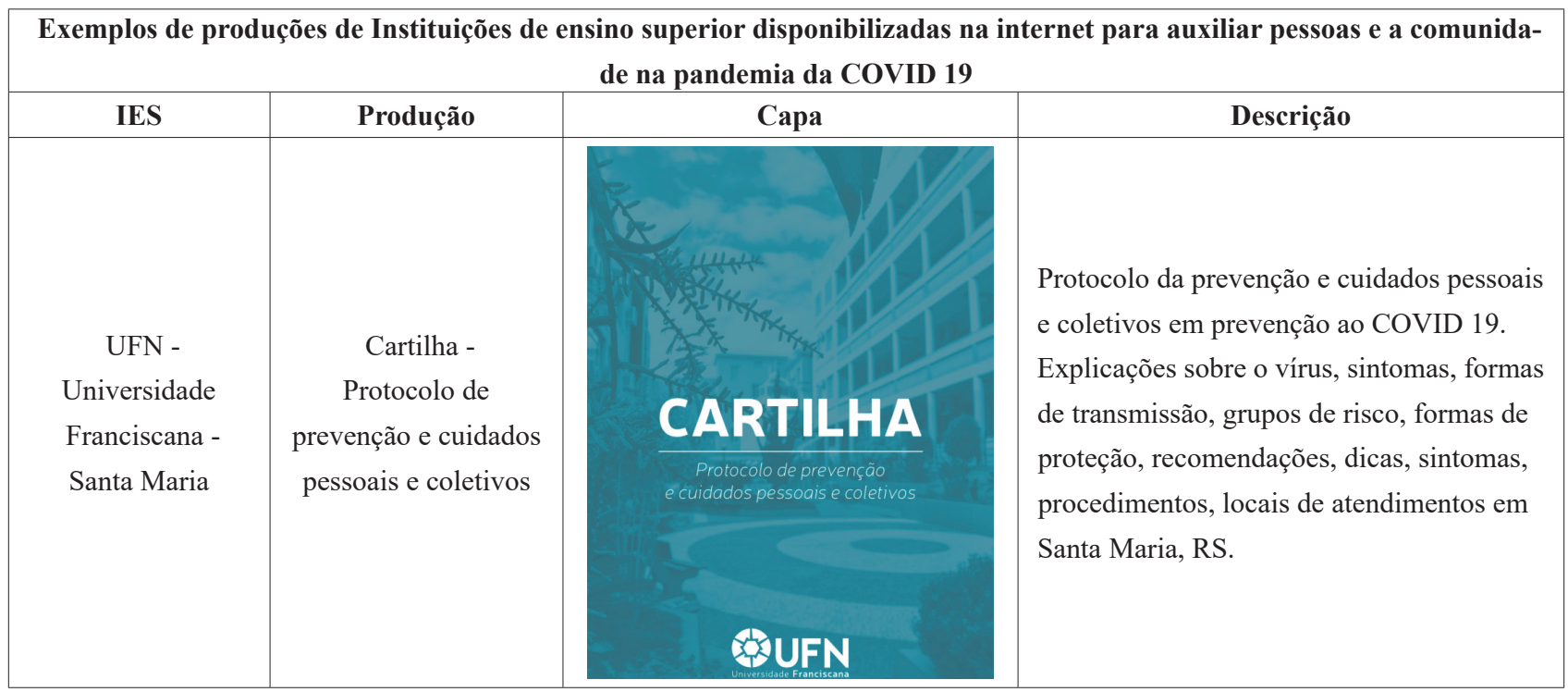




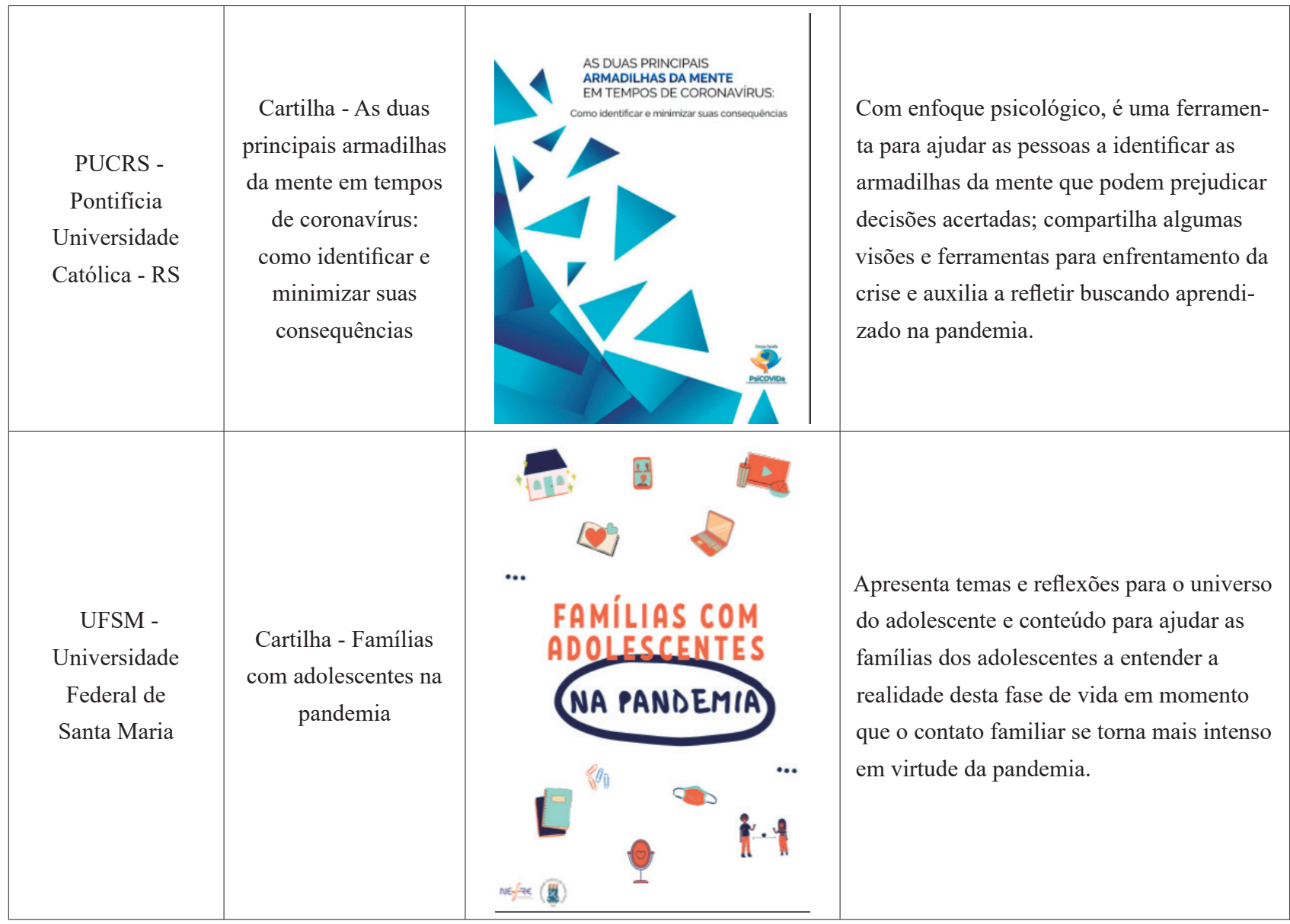

Fonte: Elaboração dos autores.

Diante desse quadro não se deve subestimar o risco, pois, se está diante de um perigo invisível, mas, real e em muitos casos letal. Por isso, a temeridade não é um sinal de fraqueza, mas representa nesse caso um aliado, pois representa um sinal de que você reconhece o perigo. "Quando não há medo, podemos estar diante da primeira armadilha da mente. O risco aqui existente é de pecarmos pela negligência, pelo descuido" (CARTILHA PUCRS).

A temática da cartilha da UFSM se volta para os adolescentes e suas famílias, identificando-os no ciclo de vida e na relação da família. A adolescência, um período do desenvolvimento humano cheio de mudanças que perpassam e impactam aspectos físicos, psicológicos e sociais.

Ao trazermos para análise as produções que veiculam na mídia, isto é, estão disponibilizadas na internet nos portais das IES em uma janela específica vinculada à COVID - 19, e configuram uma série de elementos que fazem parte do quadro 1 - dimensões da comunicação de Pierre Lévy (1999), em que identifica o meio e sua definição.

São também, as diferentes dimensões da comunicação que nos incitam a analisar as produções (cartilhas) em que se efetua um sistema de análise em torno de critérios tomados em sugestão às dimensões de Lévy (1999) agregando também, alguns elementos emprestados de critérios utilizados para análise de sites, entendido como pertinente no contexto de produções disponíveis em meio digital em páginas e portais da internet. 
Quanto a objetividade e conteúdo: as produções indistintamente apresentam-se claras quanto aos seus reais objetivos, dão conta de informar e instruir de forma muito apropriada, com clareza, objetividade e relevância do tema. A seleção dos temas e a abordagem utilizada são excelentes e cumprem um papel essencial neste momento de pandemia.

Quanto ao conhecimento da audiência e adequação: são absolutamente adequadas e pertinentes orientadas a públicos diversos e amplos (sociedade, população) não fazem restrições entre audiências, exceto a cartilha da UFSM que apresenta um extrato de públicos em que define família e adolescente, sem contudo estabelecer restrições, o conteúdo é aberto a todos que se interessarem.

Quanto a confiabilidade: os textos e propostas são extremamente confiáveis, apresentam referências e fontes, indicam representantes, contatos criadores e núcleos idealizadores do projeto. A cartilha da UFN indica e traz a referência da formação do Centro de Operações de Emergência em Saúde para Educação da Universidade Franciscana - COE-E UFN criado pela Portaria n. 32/2020. A cartilha da PUCRS é uma produção colaborativa, apresenta seus autores, titulação e vinculação a grupos de pesquisas, associados ao Programa de Pós-graduação em Psicologia da PUCRS. A cartilha da UFSM da mesma forma é uma criação colaborativa tem origem no Núcleo de Estudos Famílias e suas Relações (NEFRE) que integra o Núcleo de Estudos Interdisciplinares em Saúde (NEIS). Essas características conferem fidedignidade e confiabilidade ao produto que é a cartilha disponibilizada pelas IES. São produtos de estudo e pesquisa acadêmicas o que já configura conhecimento confiável e relevante.

Quanto à aparência, estética e linguagem: apresentam-se bastante apropriadas em termos da escolha das fontes e cores identificadoras do projeto. A linguagem é apropriada, pois as cartilhas da UFN e PUCRS, apresentam uma linguagem e estética com a seriedade que o tema requer, entretanto, fazem chamadas com fontes e cores distintas, destacando e ofertando dicas importantes, chamando a atenção para algumas questões de maior peso na textualidade. Um recurso que estabelece com a audiência um diálogo de interesses em que o produtor de antemão já sabe o que irá interessar no seu interlocutor e com respeito e delicadeza oferta isso. Este mesmo recurso é usado na cartilha da UFSM com a diferença que esta, se utiliza de aspectos e fontes mais lúdicas em função do público para o qual se direciona.

Esses três exemplos de produções de material instrucional apenas possibilitam que se perceba o quanto que a pandemia para além da preocupação e seriedade que a situação exigiu em sua fase inicial e continua a exigir de todos num processo recursivo e continuado. Apesar de tudo, não inibiu que houvessem ações imediatas para fazer a mediação e interlocução com a população, em momento em que ainda se buscava entender o fenômeno. Por sorte e competência da ciência, estas ações, ofertaram suporte e apoio através de alguns elementos, frutos da pró-atividade que atravessaram o fenômeno e se utilizaram do campo abrangente e múltiplo da midiatização numa concepção da educação em saúde que o momento exige. Nesse sentido percebe-se que o recurso se situa em uma concepção de educomunicação, que enfatiza o processo de saber necessário. 
Dessa forma, a educação/comunicação seria capaz de contribuir com o formativo dos sujeitos numa perspectiva não apenas de utilização instrumental do recurso tecnológico como dispositivo desinterditado, mas compreendendo que a trajetória da comunicação no encontro com a educação promove o entendimento das mediações como elementos multidirecionais e multidimensionais.

\section{CONSIDERAÇÕES FINAIS}

O que a pandemia nos mostra e as IES em referência vem a comprovar, é que em situações como essa, devemos reunir as forças solidárias, as capacidades e competências, para ofertar colaboração em momento de pandemia. É uma questão de ética e de responsabilidade sócio ambiental. Auxiliar a sociedade com conhecimento, ajudar a dar conta de uma situação emergencial em uma perspectiva instrucional disponibilizando e compartilhando conhecimento no sentido de ajudar que todos possam efetuar os cuidados necessários consigo e com os outros é um papel das Universidades. Ajudar a tornar o contexto de crise socioambiental e o mundo um pouco melhor é uma necessidade e uma competência educacional.

Vive-se um paradoxo, em meio a problemas gigantescos com situações calamitosas e vergonhosas do ponto de vista da desigualdade e necessidades humanas. Por um lado, nos orgulhamos e desfrutamos do desenvolvimento das ciências e tecnologias, e por outro lado percebemos que há uma longa caminhada pela frente para que possamos avançar a níveis de desenvolvimento humano e sustentável num entendimento da forma como compreende a agenda 2030, sem deixar ninguém para trás. Entretanto, ações como essas nos indicam que a utopia é possível.

\section{REFERÊNCIAS}

ASSOCIAÇÃO BRASILEIRA DE PESQUISADORES E PROFISSIONAIS EM EDUCOMUNICAÇÃO. ABPEducom. SOARES, Ismar. Vídeo-entrevista. Disponível em: https://goo.gl/y1Ypyp. Acesso em: 20 nov. 2019.

BACCEGA. M. A. Comunicação/educação e a construção de nova variável histórica. Revista do curso de Gestão de Processos Comunicacionais. São Paulo: v.14, n. 3 p. 19 - 28, set/dez. 2009.

BATISTA, D. M. T. O debate sobre o uso de técnicas qualitativas e quantitativas de pesquisa. In: MARTNELLI. M. L. (Org.) Pesquisa qualitativa: um instigante desafio. São Paulo: Veras Editoras, 1999. 
BRAGA. J. L. Comunicação é aquilo que transforma linguagens. XVIII Encontro da Compós, na PUC-MG, Belo Horizonte, MG, jun./2009.

BRAGA. J. L. Meios de comunicação e linguagens: a questão educacional e a interatividade. Linhas Críticas, v. 5 n. 9, 129-148, jul-dez/1999. Disponível em: https://doi.org/10.26512/lc.v5i9.2761

CARTA MAIOR. Entrevista com Edgar Morin, publicada originalmente em Le Monde, tradução: Aluisio Schumacher. Disponível em: https://bit.ly/3nyjiLQ. Acesso em: 29 abr. 2020.

CASTELLS, M. Redes de indignação e esperança: movimentos sociais na era da internet. Rio de Janeiro: Zahar, 2013.

CAZASSA, M. J., LUCENA-SANTOS, P., POZZA, D. R., Oliveira, M. S., \& SLAVICH, G. M. As duas principais armadilhas da mente em tempos de coronavírus: Como identificar e minimizar suas consequências. Porto Alegre, RS: PUCRS, 2020.

CITELLI. A. Tecnocultura e educomunicação. Rizoma, Santa Cruz do Sul, v. 3, n. 2, p. 63-75, dez./2015.

GIL, A. C. Como elaborar projetos de pesquisa. 6. Ed. São Paulo: Atlas, 2017.

GOMES. P. G. Midiatização: um conceito, múltiplas vozes. Revista Famecos. Porto Alegre, v. 23, n. 2. mai, jun e ago de 2016.

HJARVARD. S. Midiatização: teorizando a mídia como agente de mudança social e cultural. Matrizes. São Paulo: Ano 5 - n. 2 jan./jun. 2012. p. 53-91.

MINAYO, M. C. S. O desafio do conhecimento: pesquisa qualitativa em saúde. 10. ed. São Paulo: Hucitec, 2007.

LÉVY, P. Cibercultura. São Paulo: Editora 34, 1999.

SOARES, I. de O. Educomunicação e educação midiática: vertentes históricas de aproximação entre comunicação e educação. Disponível em: https://bit.ly/3nylZNe. Acesso 26 nov. 2019. 
THOMPSON, J. B. A mídia e a modernidade: uma teoria social da mídia. Petrópolis, RJ: Vozes, 1998.

UNIVERSIDADE FEDERAL DE SANTA MARIA. Núcleo de Estudos Família e suas Relações. Projeto do PPG em Psicologia lança cartilha para famílias com filhos adolescentes na pandemia. Disponível em: https://bit.ly/39pnOqT. Acesso em: 05 de ago. 2020.

UNIVERSIDADE FRANCISCANA. Plano de Contingência e prevenção à COVID-19. Cartilha: protocolo de prevenção e cuidados pessoais e coletivos. Disponível em: http://www.ufn.edu.br/site/ Covid19. Acesso em: 05 de ago. 2020. 